\title{
Relações de herança entre construções e entre frames: desafios da extensão do modelo construcionista para o domínio computacional no âmbito da FrameNet Brasil
}

Inheritance relations between constructions and between frames: challenges to the extension of the constructionist approach to the computational domain in FrameNet Brasil

Tiago Timponi ToRRENT (Universidade Federal de Juiz de Fora - UFJF) Ludmila Meireles LAGE (Universidade Federal de Juiz de Fora - UFJF)

Tatiane Silva Tavares (Universidade Federal de Juiz de Fora - UFJF) Adrieli Bonjour LAVIOLA (Universidade Federal de Juiz de Fora - UFJF)

\section{RESUMO}

Este trabalho tem por objetivo discutir em que medida práticas analíticas já consagradas pela Linguística Cognitiva podem ser estendidas ao dominio da Linguística Computacional. Em específico, buscamos investigar se as relações de herança entre construções - pareamentos de uma forma evocadora de um frame - modeladas computacionalmente em um Constructicon, podem ser postas em paralelo com aquelas relações estabelecidas entre os frames na base de dados da FrameNet Brasil.

Palavras-chave: Relações de Herança; Abordagens Construcionistas; Modelagem Computacional. 


\section{ABSTRACT}

This paper aims to discuss to what extent analytical practices that are already a milestone in Cognitive Linguistics can be extended to the realm of Computational Linguistics. Specifically, we aim to investigate whether inheritance relations between constructions - a pairing of a form evoking a frame - which are computationally represented in a Constructicon, may parallel frame-to-frame relations in the FrameNet Brasil database.

Key-words: Inheritance Relations; Constructionist Approaches; Computational Modeling.

\section{Introdução}

A definição de construção como um pareamento de forma e sentido e a concepção da gramática como uma rede de construções podem ser vistas como dois marcos teóricos fundadores dos modelos construcionistas, em qualquer de suas vertentes (Goldberg 2006). Ademais, o tratamento do aspecto semântico-funcional das construções nos termos propostos pela Semântica de Frames e o das relações estabelecidas entre as unidades que compõem a rede construcional da gramática em termos de relações de herança também se fazem presentes em vertentes distintas da Gramática das Construções, desde as mais cognitivistas (Croft 2001; Goldberg 1995; 2006; 2010; Langacker 1987; 1991; 2008) até aquelas baseadas em unificação (Kay \& Fillmore 1999; Boas \& Sag 2012; Fillmore 2013; Bergen \& Chang 2013).

Desde 1997, quando da criação, pelo linguista Charles Fillmore, do projeto FrameNet (http://framenet.icsi.berkeley.edu) (Fillmore et al. 2003), a interface entre Gramática de Construções e Semântica de Frames foi estendida ao domínio da Linguística Computacional, na medida em que o objetivo do referido projeto é a modelagem de uma rede de frames - estruturas de conceitos nas quais, para se entender um deles, todos os demais devem ser compreendidos (Fillmore, 1982) - associada ao material linguístico - lexical ou construcional - que a evoca. Tal rede organiza os frames através de relações de Herança, Uso, Perspectiva, Subframe, Precedência, dentre outras. 
Dado esse contexto, a proposta que aqui se apresenta é a de discutir se e em que medida as relações de herança entre construções podem ser postas em paralelo com aquelas relações estabelecidas entre os frames na base de dados da FrameNet e, por extensão, da FrameNet Brasil (http://www.framenetbr.ufjf.br), iniciativa desenvolvida na Universidade Federal de Juiz de Fora desde 2007 (Salomão 2009). Assim, pretende-se colocar em perspectiva o próprio conceito de motivação, conforme proposto por Goldberg (1995) na forma do Princípio da Motivação Maximizada, quando da extensão do modelo construcionista para o domínio da Linguística Computacional.

Para tanto, na seção 1, apresentam-se os conceitos e práticas fundamentais da FrameNet Brasil, os quais servem de ponto de partida para o desenvolvimento do Constructicon do Português Brasileiro, objeto da seção 2. Por sua vez, a seção 3 se ocupa da discussão das relações entre construções e entre frames e sua extensão ao domínio da Linguística Computacional. A seção 4 traz as considerações finais deste trabalho, as quais apontam para os caminhos a serem seguidos no âmbito da FrameNet Brasil.

\section{A FrameNet Brasil}

A FrameNet Brasil é o braço brasileiro de uma iniciativa de pesquisa em lexicografia e constructicografia ${ }^{1}$ computacionais iniciada em 1997, por Charles J. Fillmore e seus colaboradores, no International Computer Sciences Institute, em Berkeley, Califórnia. Além do projeto matriz, desenvolvido para o inglês, e da filial brasileira, há framenets ${ }^{2}$ em desenvolvimento para o espanhol, alemão, japonês, sueco, chinês, francês, italiano e coreano.

A FrameNet caracteriza-se como uma aplicação prática da teoria da Semântica de Frames, desenvolvida por Fillmore desde a década de

1. O termo constructicografia aparece em Bäckström et al. (2014:10) e se refere, em paralelo à distinção entre lexicologia e lexicografia, à descrição sistemática de generalizações linguísticas que podem ser formalizadas em um recurso construcional.

2. Neste artigo, usaremos o termo "framenet", todo em minúsculas, ao nos referirmos genericamente aos projetos, enquanto o termo "FrameNet", com "F" e "N" maiúsculos, será reservado para que se nomeiem projetos específicos. 
70 (Fillmore 1975; 1982; 1985). De acordo com essa teoria, o significado não pode ser visto como uma lista de traços semânticos a serem ou não atribuídos a uma dada entidade, mas, sim, como relativizado a uma cena - ou frame - de fundo. É o frame que possibilita que se compreenda o significado de um item lexical como o verbo comprar. Para a Semântica de Frames, só é possível compreender o sentido de comprar tendo como referência um frame no qual haja um elemento que cumpra o papel de comprador e outro que desempenhe a função de mercadoria. Mesmo que não sejam explicitamente mencionados numa sentença em que figure o verbo comprar, outros elementos podem ser elencados, tais como o vendedor e o dinheiro, sendo necessário também definir a natureza da relação entre todos esses elementos.

A Semântica de Frames, segundo seu próprio fundador, evolui da Gramática de Casos (Fillmore 1968), mais precisamente da constatação de que uma lista fechada de casos abstratos seria insuficiente para tratar adequadamente das alternâncias de valência dos itens lexicais. Tal constatação é acompanhada por outra segundo a qual é a semântica a moldar proeminentemente as possibilidades sintáticas de uma dada palavra. Assim, na Semântica de Frames, os frames sintáticos ou de caso cedem seu lugar de destaque para frames semânticos, inicialmente distintos dos frames cognitivos. Essa distinção residia no fato de que, enquanto os primeiros se manifestariam linguisticamente, os segundos teriam lugar na interpretação das sentenças e na construção do conhecimento, porém, sem serem diretamente evocados pelos itens lexicais. Posteriormente, porém, Fillmore (2008a) afirma estar em aberto a existência de uma real distinção entre frames linguísticos e frames cognitivos, uma vez que, caso exista, essa distinção se instanciaria "em um mundo em que qualquer coisa pode ser alvo do intelecto humano e do discurso" (Fillmore 2008a:12).

Definida, em seu texto mais emblemático, como "um programa de pesquisa em semântica empírica e um framework descritivo para a apresentação dos resultados de tal pesquisa" (Fillmore 1982:111), a Semântica de Frames abraçou, na década de 1990, o viés da lexicografia prática ${ }^{3}$, dando origem à Berkeley FrameNet. Nesse viés, os técnicas para a construção de recursos lexicais (vide Atkins \& Rundell 2008 para uma exposição completa sobre o tema). 
objetivos principais compartilhados por qualquer uma das framenets em desenvolvimento são (Ruppenhofer et al. 2010:):

- criar representações computacionais dos frames, os quais são definidos em termos dos seus participantes, instrumentos e circunstâncias (os Elementos de Frame - EFs) e conectados uns aos outros em uma rede de relações frame-a-frame;

- definir as Unidades Lexicais (ULs) que evocam os frames;

- anotar sentenças extraídas de corpora que exemplifiquem os padrões de valência sintático-semântica nos quais a UL pode ocorrer;

- disponibilizar o resultado do trabalho online.

Nesse sentido, a partir do exemplo do verbo comprar, apresentamos na sequência de que forma os conceitos da Semântica de Frames se manifestam nas framenets, mais especificamente na FrameNet Brasil.

Comecemos pelo próprio verbo. Na framenet, todo material lexical a ser analisado é inserido no banco de dados através da sequência lexe$m a>$ lema $>$ unidade lexical. Um lexema é uma palavra registrada em todas as suas possibilidades flexionais. O banco de dados da FrameNet Brasil, portanto, associa ao lexema comprar todas as formas de palavra assumidas por esse verbo em português. Uma vez registrado no banco o lexema, pode-se associá-lo a um frame. Entretanto, como as framenets também analisam materiais polilexêmicos, tais como palavras compostas e expressões idiomáticas, o banco de dados primeiramente associa um ou mais lexemas na constituição de um lema, para, só então, associar o lema ao frame, criando a unidade lexical (UL). Uma UL como comprar, portanto, é o pareamento do lema comprar ao frame evocado por esse verbo, no caso, o frame Comércio_comprar ${ }^{4}, o$ qual segue reproduzido na Figura 1.

A cada frame é atribuído um nome, o qual busca ser um resumo intuitivo do frame e de sua posição na rede. No caso de Comércio_ comprar, o nome indica se tratar este de um dos frames que abordam o conceito de comércio, na perspectiva do comprador.

4. Para facilitar a leitura, nomes de frames serão apresentados em fonte Courier, enquanto os nomes dos Elementos de Frame (EF) serão formatados em Versalete. 


\section{Comércio_comprar}

\begin{tabular}{|c|c|}
\hline \multicolumn{2}{|l|}{ Definiçāo } \\
\hline \multicolumn{2}{|c|}{$\begin{array}{l}\text { Este frame descreve uma transação comercial básica, envolvendo um comprador e um vendedor que trocam dinheiro e mercadorias, } \\
\text { assumindo-se a perspectiva do comprador. As palavras variam individualmente quanto aos padrōes de realização dos elementos de } \\
\text { frame. Por exemplo, a valência tipica do verbo COMPRAR é: COMPRADOR compra MERCADORIAS do VENDEDOR por DINHEIRO. }\end{array}$} \\
\hline \multicolumn{2}{|l|}{ Exemplo(s) } \\
\hline \multicolumn{2}{|c|}{ Elementos de Frame Nucleares } \\
\hline \multirow{2}{*}{\multicolumn{2}{|c|}{$\begin{array}{l}\text { Comprador o Comprador quer Mercadorias e oferece Dinheiro a umvendedor em troca. Ana comprou um casaco. Márcio } \\
\text { [buyer] comprou um livro de Carla. } \\
\text { Mercadorias o EF Mercadorias refere-se a qualquer coisa (incluindo tempo de trabalho, por exemplo), que é trocada por Dinheiro } \\
\text { [goods] } \\
\text { em uma transaçăo. Apenas um vencedor comprou os quadros. }\end{array}$}} \\
\hline & \\
\hline \multicolumn{2}{|c|}{ Elementos de Frame Năo-Nucleares } \\
\hline Dinheiro [money] & $\begin{array}{l}\text { Dinheiro refere-se ao que é dado em troca por Mercadorias em uma transação. Samuelcomprou o } \\
\text { carro por R\$12.000. }\end{array}$ \\
\hline Finalidade [purpose] & A finalidade pela qual um ato intencional é realizado. \\
\hline $\begin{array}{l}\text { Finalidade_das_mercadorias } \\
\text { [purpose_of_goods] }\end{array}$ & $\begin{array}{l}\text { A finalidade do Comprador para as Mercadorias, Eu comprei a calculadorapara facilitar o cálculo dos } \\
\text { meus débitos. }\end{array}$ \\
\hline Lugar [place] & Onde o evento ocorre. \\
\hline Maneira [manner] & $\begin{array}{l}\text { Qualquer descrição de um evento de comprar que não é dada por EFs mais especificos, incluindo } \\
\text { efeitos secundários (silenciosamente, em voz alta), e descriçōes genéricas comparando eventos (da } \\
\text { mesma forma). Isso também pode indicar caracteristicas proeminentes do Compradorque afeta a açăo } \\
\text { (presunçosamente, friamente, deliberadamente, ansiosamente, cuidadosamente). Ela alegremente } \\
\text { comprou a pedra. }\end{array}$ \\
\hline Meio [means] & O meio pelo qual uma transação comercial ocorre. Eles permitirão que vocêpague em dinheiro? \\
\hline $\begin{array}{l}\text { Periodo_de_iteração } \\
\text { [period_of_iteration] }\end{array}$ & $\begin{array}{l}\text { O período de tempo de quando o evento comercial começa a se repetir até quando é interrompido. Eu } \\
\text { comprei dele durante dez anos. }\end{array}$ \\
\hline Razāo [reason] & A Razão pela qual o evento ocorre. \\
\hline Recipiente [recipient] & $\begin{array}{l}\text { O individuo destinado pelo Comprador para receber as Mercadorias. Você já comprou três pares para } \\
\text { mim! }\end{array}$ \\
\hline Taxa [rate] & $\begin{array}{l}\text { Em alguns casos, preço ou pagamento são descritos por unidades de Mercadorias. Joana comprou } \\
\text { algumas maçăs caras por cinco reais o quilo! }\end{array}$ \\
\hline Iempo [time] & Quando o evento ocorre. \\
\hline Unidade [unit] & $\begin{array}{l}\text { Este EF indica qualquer unidade na qual mercadorias ou serviços podem ser mensurados. Geralmente, } \\
\text { isso é indicado por um SP, introduzido por por. Ana compra batataspor quilo. }\end{array}$ \\
\hline Vendedor [seller] & $\begin{array}{l}\text { o Vendedor tem posse sobre as Mercadorias e as troca pelo Dinheiro de umComprador. A maioria do } \\
\text { meu equipamento de áudio, eu comprei em uma loja de departamento perto do meu apartamento. }\end{array}$ \\
\hline
\end{tabular}

Figura 1 - O frame Comércio_comprar, conforme definido na base de dados da FrameNet Brasil. Fonte: http://www.framenetbr.ufjf.br/dados/vocabulariogenerico.

Segue-se ao nome uma breve definição do frame, na qual costumase ressaltar o papel dos principais EFs na cena. Tais EFs são listados em sequência, acompanhados necessariamente de uma definição e, quando aplicável, de um exemplo e de um tipo semântico, o qual traz 
informações ontológicas sobre o EF. Quando um EF é vital para a compreensão da estrutura de conceitos do frame, i.e. não é possível compreender o frame sem a sua presença, ele recebe o status de nuclear. Quando não, é não-nuclear5.

Os EFs caracterizam-se como funções microtemáticas, que são postuladas em relação aos frames em que tomam parte, e, não, como papéis temáticos clássicos, oriundos de uma lista finita. Segundo Salomão (2009:173):

A necessidade da postulação dessas Funções Microtemáticas em parte responde à inadequação das nomenclaturas anteriores, que, não tendo conseguido jamais apresentar um repertório consensual de Funções Temáticas, empregam algumas designações (Tema, por exemplo) com frustrante imprecisão.

Quando da análise de uma UL, os EFs serão convertidos em etiquetas semânticas atribuídas ao material linguístico que se encontra na localidade sintática da UL. O processo de anotação semântica é acompanhado de uma análise sintática, que atribui Funções Gramaticais (FGs) e Tipos Sintagmáticos (TSs) a esse mesmo material linguístico. Cada framenet tem definido o conjunto de FGs e TSs relevante para sua língua alvo, considerada a classe de palavras da UL a ser analisada, uma vez que as framenets realizam anotações lexicográficas não só para verbos, mas, também, para nomes, adjetivos, advérbios e preposições. Para o português brasileiro, por exemplo, ULs verbais podem tomar EFs que desempenham as funções sintáticas de Argumento Externo (Ext), Objeto Direto (ObjD), Objeto Indireto (ObjInd) ou Dependente (Dep). Quanto aos TSs, são levantados tanto os tipos de sintagma mais comuns - tais como NPs, PPs, VPs -, como tipos de cláusulas - adverbiais, completivas, relativas - e núcleos nus - Ns, Vs, Adjs. ${ }^{6}$

5. EFs não-nucleares podem ser divididos entre Periféricos e Extra-temáticos, apesar de essa informação não ser disponibilizada no relatório do frame. A diferença entre essas duas subcategorias reside no fato de que, enquanto EFs periféricos trazem informações circunstanciais sobre o frame, geralmente relacionadas à UL na forma de adjuntos, os EFs extra-temáticos estão relacionados a outras ULs e construções que aparecem colocadas com a UL alvo, dentro de sua localidade sintática.

6. Para um discussão detalhada dos GFs e TSs utilizados pela FrameNet Brasil, bem como sobre as escolhas teórico-metodológicas que embasam sua postulação, vide Torrent \& Ellsworth (2013). 
A anotação é realizada através de software próprio, a FrameNet Brasil Webtool. Na Webtool, cada sentença é tratada como um conjunto de camadas, nas quais se vinculam as etiquetas para os FEs, FGs e TSs ao material linguístico sendo analisado. A Figura 2 traz a tela de anotação da sentença (1), extraída do corpus NURC-RJ ${ }^{7}$, na qual o informante relata a experiência de ter assistido a um espetáculo teatral no Rio de Janeiro.

(1) Eu comprei entrada pra ir assistir a uma determinada noite. (NURC-RJ)

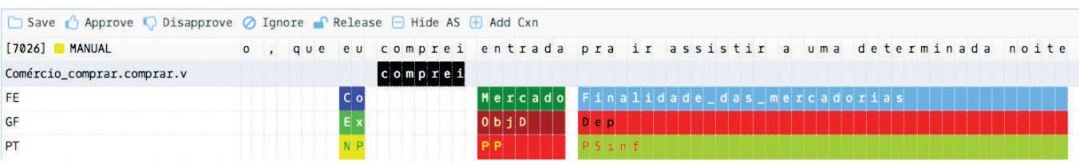

Figura 2 - Tela de anotação de sentença contendo a UL comprar. A camada FE (do inglês, Frame Element) traz as etiquetas semânticas oriundas do frame Comércio_comprar, enquanto as camadas GF (de Grammatical Function) e PT (de Phrase Type), trazem, respectivamente, as funções gramaticais e tipos sintagmáticos atribuídos ao material linguístico que instancia cada EF.

Note-se, na Figura 2, que a UL vem marcada em preto com as letras brancas. Essa notação distingue ULs em todas as framenets. Ao pronome de primeira pessoa $e u$ foram atribuídas as etiquetas COMPRADOR, Ext e NP; já a entrada, foram atribuídas as etiquetas MERCADORIA, ObjD e NP. Vê-se, assim, que os dois EFs nucleares do frame manifestam-se nas funções gramaticais mais proeminentes da sentença. Já o elemento não-nuclear FINALIDADE_DAS_MERCADORIAS aparece em função adjuntiva, como um Dep que se instancia na forma de uma sentença infinitiva preposicionada (PSinf).

A sucessiva anotação de sentenças extraídas de corpora subsidia outro tipo de relatório da FrameNet Brasil: o de entrada lexical, disposto na Figura 3. Neste relatório, apresenta-se um verbete para a UL, o qual traz o frame evocado por ela, a definição de seu significado e informações sobre sua valência sintático-semântica, a qual é calculada automaticamente a partir das anotações. 


\section{comprar.v}

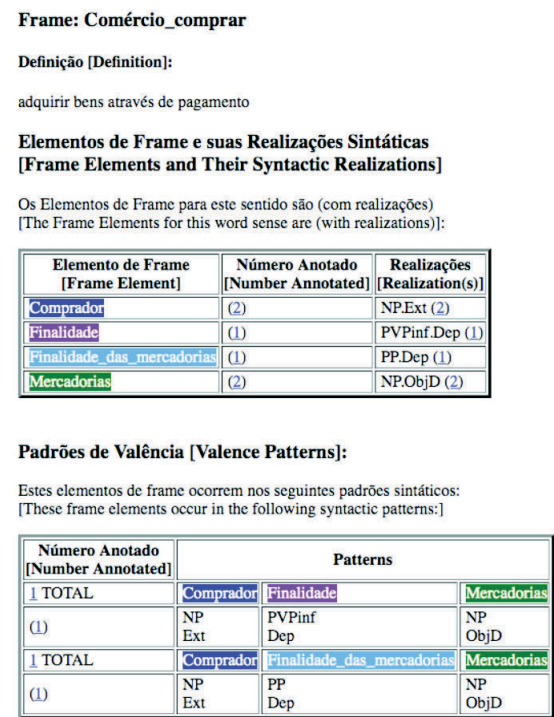

Figura 3 - Relatório de entrada lexical da UL comprar na FrameNet Brasil. Fonte: http://www.framenetbr.ufjf.br/dados/vocabulario-generico.

Por fim, as framenets, como o próprio nome indica, não se constituem em uma mera lista de frames, mas, sim, em uma rede, a qual é estruturada por um conjunto de relações frame-a-frame tais como: Herança, Uso, Perspectiva, Subframe e Precedência. ${ }^{8}$

A relação de Herança é uma relação do tipo é um, ou seja, o frame filho é um tipo mais específico do frame pai. Como toda relação entre frames proposta nas framenets é, na verdade, uma relação entre os EFs desses frames, cada EF do frame pai precisa, na relação de Herança, ter um EF equivalente ou mais específico no frame filho. Já na relação de Uso, o frame filho pressupõe a existência do frame pai para sua compreensão. Nesse caso, não é necessário haver correspondência de todos os EFs.

8. Há ainda as relações Causativo_de, Incoativo_de e Veja_também, as quais não são relevantes para o tema deste artigo. Para mais informações sobre essas relações, veja-se Ruppenhoffer et al. (2010). 
A relação de Perspectiva, constitutiva da própria noção de frame, indica que um dado frame é um dos possíveis pontos de vista de uma cena não-perspectivizada. Já as relações de Subframe e Precedência definem, respectivamente, os sub-eventos de um evento complexo e a ordem em que ocorrem. Na Figura 4 exemplificam-se essas relações, representadas através de setas coloridas no FrameGrapher, ferramenta da Berkeley FrameNet para a visualização das relações entre os frames. Escolhemos como exemplo os frames relativos ao comércio, por ser este um dos cases mais famosos da Semântica de Frames (Fillmore $1985 ; 2008 b)^{9}$.

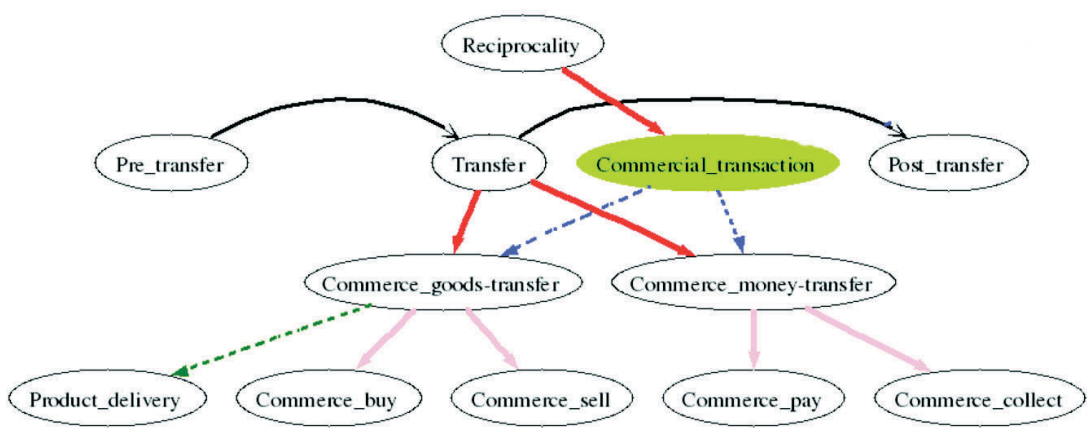

Figura 4 - Rede de relações dos frames relativos à transação comercial. Uma seta vermelha indica relação de Herança; a verde, Uso; a rosa, Perspectiva; a azul, Subframe e a preta, Precedência. Fonte: https://framenet.icsi.berkeley.edu/ fndrupal/FrameGrapher.

Como pode-se observar na referida figura, o frame Transação_comercial herda do frame Reciprocidade, indicando que uma transação é um tipo de ato recíproco. No que concerne à estrutura de eventos, a Transação_comercial pode ser dividida em dois subframes: a transferência das mercadorias e a transferência do dinheiro. Note-se que não há uma relação de Precedência entre eles, uma vez que podem ocorrer em qualquer ordem (há casos em que primeiro se paga para depois se obter a mercadoria e vice-versa).

9. Apesar de parecerem semelhantes, respectivamente, às relações semânticas de hiponímia, pressuposição e meronímia, as relações de Herança, Uso e Subframe não são idênticas a estas, principalmente, pelo fato de que, enquanto as primeiras são estabelecidas entre itens lexicais - ou, no máximo, entre synsets, no caso da WordNet (Fellbaum 1998) -, as últimas se estabelecem entre sistemas de conceitos, ou frames. 
O frame Comércio_transferência_de_mercadorias é, por sua vez, um frame neutro que pode assumir duas perspectivas: a do comprador-em Comércio_comprar-, ou a do vendedor-em Comércio vender. Como a entrega de um produto pressupõe que tenha havido a relação de transferência de mercadorias, uma relação de Uso liga o frame Entrega_de_produto ao frame Comércio_transferência_de_mercadorias.

Por fim, as setas pretas indicam a relação temporal entre os frames que indicam a noção de transferência, os quais se relacionam por Herança aos frames de comércio.

Como se observa, o esforço de descrição lexicográfica desenvolvido nas framenets é capaz de gerar um conjunto de dados de alta relevância para a descrição dos idiomas-alvo de cada iniciativa. Ao atribuírem-se etiquetas semânticas e sintáticas para o material linguístico, ao mesmo tempo em que se organizam os frames em rede, cria-se um recurso capaz não apenas de registrar informações sobre a semântica dos itens lexicais, mas, também, acerca do comportamento morfossintático desses elementos semânticos. Nesse sentido é que se postula que a anotação lexicográfica das framenets seja inspirada construcionalmente, ao fornecer uma análise da construção de valência associada aos itens lexicais (vide Fillmore 2013).

Ainda assim, há casos que não podem ser analisados estritamente em termos das propriedades valenciais dos itens lexicais, dentre os quais destacam-se as expressões idiomáticas, construções de aumento de valência, gapping, dentre outros (Fillmore 2008b). Por esse motivo, para além do recurso lexical, a Berkeley FrameNet iniciou um projeto complementar para a criação de um repositório de construções para o inglês, um Constructicon, caminho que vem sendo seguido pela Japanese FrameNet (Ohara 2013), pela Swedish FrameNet (Lyngfelt et al. 2012) e pela FrameNet Brasil (Torrent et al. 2014). Na seção seguinte, apresentaremos essa iniciativa e seu desenvolvimento para o português brasileiro.

\section{O Constructicon do Português Brasileiro}

Dizer que um constructicon é um repositório de construções de uma língua não é o mesmo que afirmar que ele seja uma versão eletrônica 
de uma Gramática de Construções. Segundo Fillmore et al. (2012: 309-310), um Constructicon tem por objetivo registrar as propriedades semânticas e gramaticais das construções, além de ligá-las a sentenças anotadas que exemplifiquem a construção sendo descrita, sem, necessariamente, comprometer-se com o objetivo de ser um registro eletrônico completo de todas as construções da língua, mesmo porque, enquanto recurso desenvolvido complementarmente a uma framenet, um constructicon precisa dar conta daqueles fenômenos que não podem ser resolvidos através da anotação - construcionalmente inspirada - que se pode encontrar no recurso lexicográfico.

Nesse contexto, enquanto as framenets se ocupam de criar uma rede de frames, definidos em termos de seus EFs, ao mesmo tempo em que associam material lexical a esses frames - as ULs - e atestam seu uso em corpora, um constructicon tem os seguintes objetivos:

- criar representações computacionais das construções, definidas em termos de seus elementos constituintes (os Elementos do Construto - ECs) e conectadas umas às outras em uma rede de relações;

- anotar sentenças extraídas de corpora, construtos, que exemplifiquem a forma como as construções licenciam a expressão linguística;

- disponibilizar o resultado do trabalho online.

A fim de se ilustrar o tipo de fenômeno linguístico que motiva o desenvolvimento de um constructicon, observe-se o exemplo (2), extraído do corpus NURC-RJ.

(2) Não dá pra ver não (NURC-RJ)

Em (2), observa-se uma construção com o verbo dar. Na tentativa de traçar uma análise via metodologia da FrameNet Brasil, primeiramente, escolhe-se uma UL alvo para se iniciar a anotação. Se tomamos por UL o verbo dar e buscarmos um frame que seja evocado por esse verbo, encontramos o frame Dar, cuja definição é apresentada na Figura 5. 
Um Doador transfere um Tema a um Recipiente. Este frame inclui apenas aç̋es iniciadas pelo Doador (aquele que inicia o processo exercendo a posse sobre o Tema), As sentenças (mesmo as metafóricas) devem atender aos seguintes critérios: de principio, o Doador detém a posse sobre o İema; após a transferência, o Doador não mais possui o İema, o qual passa a ser do Recipiente. Plinio deu um presente muito caro para sua

Figura 5 - Definição do frame Dar na FrameNet Brasil. Fonte: http://www. framenetbr.ufjf.br/dados/vocabulario-generico.

Se observarmos a definição na Figura 5, veremos que ela não descreve a cena evocada pela sentença (2) - não há um DoADOR transferindo um TEMA a um RecipIENTE. Em vez disso, tem-se o frame Pos sibilidade, exibido na Figura 6, o que se verifica na paráfrase da sentença: "Não é possível ver, não". Contudo, como anotar tal sentença no referido frame se não é o verbo dar que o evoca? ${ }^{10}$

\section{Possibilidade}

\section{Definição}

Um Evento_possivel é considerado como tendo alguma probabilidade de ocorrência, se pertencer a alguma Condição adicional (geralmente mplicita). A Condição, se declarada ou implicita, geralmente se refere à decisá de um agente de tentar trazer algo sobre o Evento_possivel.

Figura 6 - Definição do frame Possibilidade na FrameNet Brasil. Fonte: http://www.framenetbr.ufjf.br/dados/vocabulario-generico.

Diante desta situação, surge a necessidade de um novo recurso, desenvolvido para atender a estruturas mais complexas do que as propriedades de valência de um item lexical e/ou mais idiomáticas: o constructicon. Para iniciar a implementação do Constructicon do Português Brasileiro, a família de construções Para Infinitivo (Torrent 2009; Lage, 2013) foi escolhida. As construções que formam essa família compartilham o esquema sintático $\left[\mathrm{NP}_{1} \mathrm{~V} \mathrm{AP} / \mathrm{NP}_{2}\right.$ para $\left(\mathrm{NP}_{3}\right)$ $\mathrm{V}_{\mathrm{INF}}$ ] ou são relacionadas a ele através de relações de herança. Todas as construções descritas em Torrent (2009) e Lage (2013) herdam da Construção Adjuntiva final infinitiva, cujo esquema formal é [para

10. Não se ignora aqui que elementos semânticos do verbo dar, em especial o esquema imagético subjacente Fonte-Caminho-Alvo, atuem metaforicamente na construção do significado de possibilidade do exemplo (2). Porém, no âmbito do recurso computacional FrameNet, ainda não é possível modelar tal atuação. 
(NP) $\mathrm{V}_{\mathrm{INF}}$ ] e cuja semântica se relaciona à finalidade. Note-se que o uso dos parênteses nas notações acima indica que o sujeito do verbo infinitivo pode ou não vir explícito.

No que tange à contraparte semântica, as construções dessa família evocam o frame Finalidade ou algum outro relacionado a ele. Nesse sentido, relacionam-se a "um esquema cognitivo de movimento em direção a um alvo", este representado pela resultante desejada de uma determinada ação (Torrent 2009: 75).

Ao iniciarmos as análises das construções da rede escolhida, uma questão impôs-se: quais construções necessitam de um tratamento construcional e, por outro lado, quais poderiam ser tratadas via anotação lexicográfica? Iniciamos a discussão considerando o exemplo (3).

(3) Ela... era analfabeta... então pedia para a gente escrever o jogo... (NURC-RJ)

Na sentença (3), vemos um exemplo da Construção Manipulativa com o verbo pedir. Segundo Torrent (2009), nessa construção, um manipulador faz com que um manipulado realize uma ação desejada pelo primeiro. No caso do exemplo, a senhora analfabeta, que era apontadora do Jogo do Bicho, fazia com que o informante e pessoas de seu convívio escrevessem os jogos para ela. Se tomarmos tal verbo por UL e realizarmos uma anotação lexicográfica, obteremos a configuração constante em (4).

(4) Ela... era analfabeta... então [PEDIA $\left.{ }^{\mathrm{UL}}\right]$ [para a gente escrever o jogo $\left._{\text {Destinatírio/Mensagem }}\right] \ldots \mid$ Falante $=$ CNI

Tomando-se o verbo pedir como UL, a sentença será anotada, satisfatoriamente, no frame Pedir, cuja definição prevê que "neste frame, um Falante pede alguma coisa a um Destinatário ou que ele realize alguma ação". Tem-se os EFs Mensagem e DestinatáRIO representados pelo sintagma para gente escrever o jogo e o EF FALANTE apresenta-se como uma Instanciação Nula Construcional (CNI), uma vez que se instancia apenas na desinência verbal de pedia. 
Para verificar se o frame em questão é evocado mesmo pelo verbo ou pela construção, caso este em que a anotação lexicográfica satisfatória acima seria uma coincidência, analisamos, então, outra sentença que também evoca o frame Pedir, mas em que não se instancia uma construção pertence à Família Para Infinitivo, conforme a Figura 7.

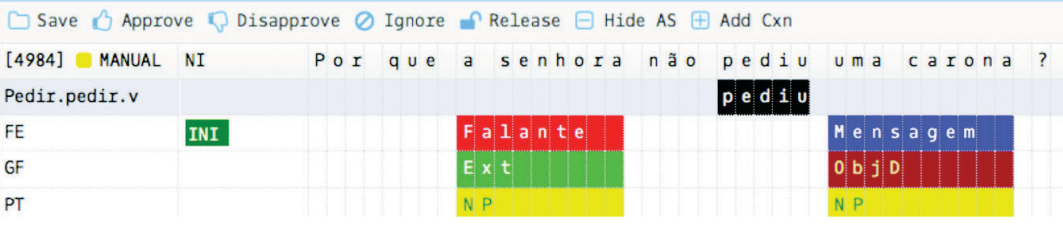

Figura 7 - Anotação lexicográfica da UL pedir no frame Pedir.

Na Figura (7), observamos que a sentença anotada, mesmo não apresentando a construção Para Infinitivo, obtém a mesma análise. Isso aponta para o fato de que, no caso da Construção Manipulativa, definida por Torrent (2009), não há necessidade de anotá-la no Constructicon, uma vez que a anotação lexicográfica é suficiente para capturar o sentido evocado pela construção.

Entretanto, se analisamos construções como o exemplo em (2), faz-se necessário adotar outro método de anotação que não o lexicográfico, uma vez que, como já se viu, o verbo dar, nesse caso, não é o evocador do frame Poss ibi lidade, mas, sim, a Construção Modal Epistêmica com Dar, definida na Figura (8).

\section{Modal_epistêmica_dar []}

\begin{tabular}{|c|c|}
\hline Definiçāo & \\
\hline Um Modalizador_epistêmi & ico, necessariamente o verbo "dar", modifica um VP_para_inf que codifica uma ação ou evento possível. \\
\hline Exemplo(s) & 다 \\
\hline Elementos da Construç & \\
\hline $\begin{array}{l}\text { Modalizador_epistêmico } \\
\text { [Epistemic_modal] }\end{array}$ & $\begin{array}{l}\text { Expressão que adiciona ao Vinf a noção de modalização epistêmica de possibilidade. Nesta construção, o } \\
\text { Modalizador_epistêmico é especificado lexicalmente como o verbo "dar". }\end{array}$ \\
\hline
\end{tabular}

Figura 8 - Construção Modal Epistêmica com Dar, conforme definida no Constructicon da FrameNet Brasil. Fonte: http://www.framenetbr.ufjf.br/dados/ vocabulario-generico. 
Considerada essa construção, a anotação de (2) ficaria como exibida em (5).

Não [dá $\left.{ }_{\text {ModalizADOR_EPISTÊMICO }}\right][$ pra ver VP__PARA_INF $]$

Note-se que a sentença (5) não foi marcada para os EFs de Pos sibilidade. Diferentemente do caminho tomado pela Berkeley FrameNet, cujo Constructicon apresenta definições de ECs que mesclam aspectos sintáticos e semânticos, na FrameNet Brasil, os ECs são definidos exclusivamente em termos de suas propriedades formais, sendo que, posteriormente, são mapeados aos EFs, caso a construção evoque um frame.

Contrastes analíticos como os apresentados acima foram realizados para todas as construções da Família Para Infinitivo no trabalho de Lage (2013), que acabou por identificar, dentre as 26 construções elencadas por Torrent (2009), 11 que deveriam ser tratadas como construções no Constructicon, enquanto as demais poderiam ser tratadas apenas via anotação lexicográfica. O princípio por detrás dessa decisão analítica é o da Não-Redundância, o qual evita a duplicação de esforços, o desperdício de espaço de armazenamento, e a inconsistência de dados. Lage (2013: 100) esclarece:

Se uma mesma informação for anotada duas vezes em ambientes diferentes [lexicon e constructicon], quando for preciso realizar uma atualização, essa deverá ser feita, também, duas vezes. A segunda questão é o desperdício de espaço de armazenamento. Ao armazenar a mesma informação duas vezes, ocupamos um espaço que poderia ser utilizado para arquivar outras informações. Isso pode gerar problemas maiores para bancos de dados grandes. Por fim, há a questão da inconsistência de dados gerada pela anotação redundante. Ao se atualizar uma informação anotada duplamente em somente um dos ambientes utilizados para o armazenamento, uma incoerência entre os dados pode ser gerada se o mesmo não for feito no outro ambiente.

Assim, foram estabelecidos critérios para se definir o que é uma construção no âmbito da FrameNet Brasil, os quais se apresentam na forma de três perguntas: 
Critério 1: Sendo X um material lexicalmente especificado, existe $\mathrm{X}$ na construção em potencial?

Critério 2: Sendo $F$ um frame e $X$ um material lexicalmente especificado, X evoca F?

Critério 3: Sendo F um frame e $\mathrm{X}$ um material lexicalmente especificado, $\mathrm{X}$ evoca $\mathrm{F}$ em outro padrão de valência?

Em relação ao primeiro critério, visto que a anotação lexicográfica tem a UL como unidade básica de análise, "é condição sine qua non a existência de algum item lexical específico para que esse tipo de anotação deva ocorrer" (Lage 2013: 102). Se a resposta for negativa, deve-se encaminhar a análise para o Constructicon, mas, se for positiva, devemos nos dirigir ao segundo critério.

Como a UL é a unidade básica de análise da anotação lexicográfica, evocar um frame é condição sine qua non para o objeto sob discussão. "Se a construção em potencial não evoca frame, não pode ser abordada como UL e, destarte, exige um tratamento construcional" (Lage 2013: 103). Sendo a resposta positiva, partimos, então, para o terceiro e último critério.

Lage (2013: 104) afirma, por fim, que "se uma unidade de material lexicalmente fixo for capaz de evocar um mesmo frame em padrões de valência diferentes significa que o frame foi evocado pela unidade alvo (também)". Assim, esse objeto deveria ser tratado via abordagem lexicográfica. A resposta negativa, entretanto, nos conduz ao tratamento construcional.

Através de tais apontamentos, tem-se a definição formal de construção no âmbito da FrameNet Brasil e, consequentemente, a definição do escopo de cada um dos dois recursos: o lexicon e o constructicon. Entretanto, tais critérios ainda não são capazes de responder a outra questão: como lidar com a estruturação da rede de construções armazenadas em um constructicon? A busca por uma resposta a essa questão será objeto da próxima seção. 


\section{Relações entre Construções e entre Frames}

O Berkeley Constructicon propõe, para algumas construções, a existência de uma relação de Herança. Tal caso se verifica, por exemplo, para a Construção Infinitival_relative_modal, a qual, conforme mostra a Figura 9, herda da Construção Relative_clause.

Infinitival_relative_modal

Inherits Relative clause.

- A noun phrase, the Head, is modified by a $t o$-marked non-finitve VP, the Infinitival_relative.

ex.: We finally found [

- Head(head): The Head is a noun phrase modified by the relative clause.We finally found [heoda book] to read to our daughter. - Infinitival_relative(inf): The Infinitival_relative is a to-marked infinitival clause that modifies the Head, and which indicates some variety of modality. We finally found a book [infto read to our daughter].

Figura 9 - Definição da Construção Infinitival relative modal no Berkeley Constructicon. Fonte: http://www1.icsi.berkeley.edu/ hsato/cxn00/21 colorTag/ index.html.

Entretanto, tal relação não se encontra modelada, na base de dados do Constructicon, da mesma forma como as relações entre frames o são. Em outras palavras, não há, ainda, no repositório de construções de Berkeley, uma formalização das relações entre construções.

No âmbito da FrameNet Brasil, já desde a implantação do Constructicon, busca-se modelar computacionalmente as relações entre construções, investigando, ainda, a possibilidade de se propor um paralelismo entre elas e as relações que se estabelecem entre os frames. Como ponto de partida para esse trabalho, faz-se necessário, primeiramente, discutir o que se entenderá por herança construcional nesse contexto.

\subsection{Relações de Herança nas Gramáticas de Construções de Berkeley e Cognitivista}

A Gramática de Construções de Berkeley (Kay \& Fillmore 1999; Fillmore 2013), na qual se inspira o desenvolvimento do Constructicon, trabalha com a noção de Herança Completa, a qual se define da seguinte maneira: "Quando uma construção herda da outra, a primeira 
contém todas as informações da segunda e - nos casos em que essa relação de fato diz algo - mais" (Kay \& Fillmore 1999: 7). A título de exemplo dessa relação, os autores apresentam a relação existente entre a Construção Núcleo-Complemento e a Construção de Sintagma Verbal. A primeira, representada na Figura 10, é composta por dois signos filhos: um Núcleo (Head), marcado positivamente para o traço lexical (lex), e um ou mais Complementos (Fillers), os quais se manifestam localmente (loc +$)$, à direita do Núcleo.

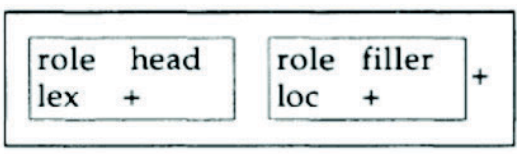

Figura 10 - Construção Núcleo-Complemento (Kay \& Fillmore 1999: 7).

Já para a Construção de Sintagma Verbal, é necessário especificar mais atributos: a categoria do Núcleo precisa ser Verbo (cat v) e a função gramatical do Complemento não pode ser a de sujeito (gf -subj). Logo, essa construção tem sua representação proposta conforme a Figura 11.

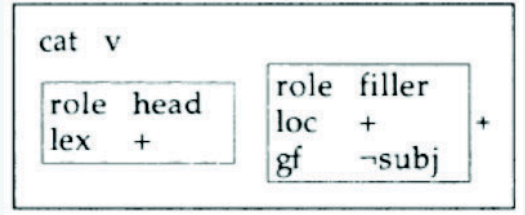

Figura 11 - A Construção de Sintagma Verbal (Kay \& Fillmore 1999: 8).

Considerando-se que as construções de uma língua se relacionam em uma rede de heranças, uma forma mais econômica e genérica de representar a Construção de Sintagma Verbal seria, portanto, a apontada na Figura 12, na qual apenas as informações adicionais são representadas, juntamente com a informação de que a Construção de Sintagma Verbal herda da Construção Núcleo-Complemento (HC). 


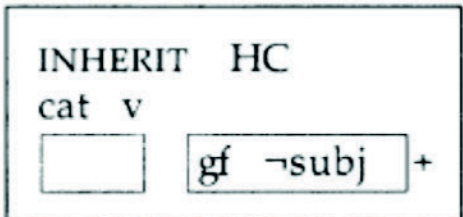

Figura 12 - A Construção de Sintagma Verbal, representada através da relação de Herança (Kay \& Fillmore 1999: 8).

Quando o Berkeley Constructicon propõe, mesmo informalmente, que a Construção Infinitival_relative_modal herda de Relative_clause, é a esse tipo de herança que a anotação se refere. Outros modelos de Gramática de Construções, entretanto, trabalharão com noções distintas da de Herança Completa. A vertente Cognitivista (Goldberg 1995; 2006), por exemplo, propõe tipos diferentes de relações de herança cujo objetivo é o de explicar como uma construção herdeira é motivada pela construção-mãe. Nesse caso, trabalha-se com a noção de Herança Normal (Goldberg 1995), a qual permite não apenas herança múltipla, mas, também, parcial e sobreposta.

Goldberg (1995), propõe quatro relações de herança para dar conta da rede de construções na qual figura a Construção Ditransitiva: metáfora, polissemia, instanciação e subparte. Segundo a autora, laços metafóricos uniriam, por exemplo, a Construção de Movimento Causado - "Paulo chutou a bola pro gol" - à Construção de Discurso Reportado - "Maria contou a história para os filhos ". Já os laços polissêmicos ligariam modulações do sentido de uma construção entre si. A Construção Dativa, por exemplo - "Paulo deu um livro para Maria" -, ligar-se-ia por polissemia a outras construções em que a transferência do bem não ocorre necessariamente, mas é prometida - "Paulo prometeu um livro para Maria" - ou então é perspectivizada em função do trabalho realizado para que ocorra - "Paulo assou um bolo para Maria" - (vide Ferrari 2011 para outros exemplos e Kay 2005 para uma crítica a esse modelo).

A herança por instanciação ocorreria quando uma dada construção, geralmente idiomática, é um caso específico da construção mãe. Por exemplo, sentenças como "Paulo jogou o casamento pela janela", são construtos que instanciam a Construção de Movimento Causado, trazendo uma semântica idiomática própria. Por fim, os laços de subparte 
ligariam à construção mãe uma construção filha que é composta por parte dos elementos da mãe, apresentando sentido próprio. As sentenças " $O$ chão secou" e "O Pedro secou o chão" são licenciadas por construções ligadas entre si por subparte: a construção mãe seria a Transitiva, enquanto a filha seria a Ergativa. O laço de subparte se revelaria na medida em que o SN Agente da Transitiva não se manifesta na Ergativa.

As relações entre construções propostas na Gramática Cognitivista das Construções operacionalizam um princípio fundador dessa abordagem: o Princípio da Motivação Maximizada, segundo o qual, se duas construções são relacionadas sintaticamente, uma delas é motivada pela outra semanticamente (Goldberg 1995: 67). Em face disso, colocam-se para o desenvolvimento do Constructicon do Português Brasileiro, como recurso complementar à FrameNet Brasil, as seguintes questões:

- Seria possível, na modelagem das relações entre as construções, trabalhar exclusivamente com a Herança Completa (Fillmore \& Kay 1999)?

- Seria possível, nessa mesma modelagem, incorporar os laços de herança definidos pela Gramática Cognitivista das Construções (Goldberg 1995)?

- Seria possível acomodar o Princípio da Motivação Maximizada no Constructicon do Português Brasileiro?

A fim de refletir sobre essas perguntas, passamos, a seguir, à análise de construções já modeladas no Constructicon do Português Brasileiro, sejam elas pertencentes à Família Para Infinitivo ou à das Construções Binominais (Brodbeck 2010; Tavares 2014).

\subsubsection{O caso da Construção Volitiva}

A Construção Volitiva, exemplificada em (6), caracteriza-se, formalmente, pelo esquema [NP $\mathrm{V}_{\mathrm{COP}} \mathrm{AP}_{\text {DOIDO/LOUCO }}$ para (NP) $\mathrm{V}_{\mathrm{INF}}$ ]. Nessa construção, atribui-se ao sujeito da cópula uma vontade extrema de que o evento codificado no VP infinitivo regido por para se realize (Torrent 2009; 2015).

(6) O menino deve ser louco para comer açúcar. (NURC-RJ) 
Essa construção respeita os critérios propostos por Lage (2013) para definição dos tipos de fenômenos linguísticos a serem tratados pelo Constructicon do Português Brasileiro, uma vez que (i) há um material lexicalmente especificado - os adjetivos doido e louco, (ii) esses adjetivos evocam frames, porém (iii) só evocam o frame Desejar - Figura 13 - na construção em Para Infinitivo.

\section{Desejar}

\section{Definição}

Um Experienciador deseja que umEvento ocorra. Em alguns casos, o Experienciador é um participante ativo no Eventó e, em tais casos, o Evento

por si só geralmente nåo é mencionado, mas, sim, algum participante_focal, o qual está subordinadamente envolvido no Evento. Geralmente,

de uma palavra neste frame implica que o Evento especifico não tenha acontecido ainda, mas que o Experienciador acrecite que ele poder

Eu apenas queria um pedaço de doce.. A empresa estava ansiosa para ele deixá.la o mais rápido possivivel. Susana realmente deseja que

Figura 13 - Definição do frame Desejar na FrameNet Brasil. Fonte: http:// www.framenetbr.ufjf.br/dados/vocabulario-generico.

Torrent (2015) argumenta que a Construção Volitiva herda da Construção Adjuntiva Final Infinitiva, a qual, por sua vez, evoca o frame Finalidade - Figura 14. Na FrameNet, uma relação de Uso conecta esses dois frames, modelando o fato de a cena da Finalidade referir-se, em parte, à de Desejar, na medida em que uma Finalidade é um Evento que um AgEnte deseja que se realize ${ }^{11}$.

\section{Finalidade}

Definição

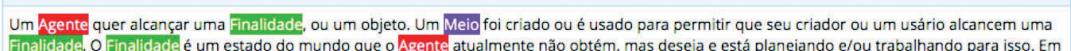
alguns casos, é difícil decidir se um sintagma nominal metonimicamente representa o Agente ou o Meio (Por exemplo: $O$ objetivo [deste papel/seminário/projeto] é determinar .... Nós marcamos esses sitagmas como Agenté na primeira camada, mas também os anotamos como Meio em uma secunda camada de anotação. Em alguns casos, um Restritoir no estado de coisas do Finalidade pode ser proeminente como um constituinte separado. Falar sobre o Finalidade frequentemente inclui a meção de um Domínio para o qual o Finalidadé do Agente é relevante. 0 objetivo modesto Americano de um aumento de três vezes na capacidade de reconhecer este fa

Figura 14 - Definição do frame Final idade na FrameNet Brasil. Fonte: http:// www.framenetbr.ufjf.br/dados/vocabulario-generico.

11. Outras relações entre Finalidade e Desejar poderiam ser propostas, dentre as quais a de metonímia. Porém, a FrameNet ainda não modela tais relações. Trabalho de pesquisa de doutorado de Maucha Andrade Gamonal tem se dedicado, atualmente, à inclusão da relação metonímica na FrameNet Brasil. 
Considerado esse contexto, dois caminhos poderiam ser buscados para se modelar, no Constructicon do Português Brasileiro, a relação de herança entre a Construção Adjuntiva Final Infinitiva e a Construção Volitiva. São eles:

- Herança Completa: como a Construção Volitiva inclui o VP infinitivo regido por para, que é a contraparte formal da Construção Adjuntiva Final Infinitiva, poder-se-ia argumentar que a primeira herda da segunda, uma vez que contém toda a informação desta e mais.

- Herança Normal: além de ser motivada pela Construção Adjuntiva Final Infinitiva, a Construção Volitiva herda, também, por instanciação, da Construção Predicativa, dado que apresenta um uso idiomático dos adjetivos doido e louco.

Apesar de, aparentemente, termos duas boas soluções para o problema da extensão para o domínio computacional das relações entre construções propostas pelas análises teóricas dessa construção, há problemas a serem resolvidos. Primeiramente, considerando-se a aplicação do Princípio da Motivação Maximizada, as relações entre as duas construções supramencionadas e os frames por elas evocados parecem ir em direções opostas: considerada a Herança Completa, a Construção Adjuntiva Final Infinitiva seria responsável por parte das informações contidas na Construção volitiva, enquanto, por outro lado, a relação de Uso entre os frames Finalidade e Desejar aponta para o fato de que parte daquele se refere a este.

Em segundo lugar, mesmo que se considere que transformações de inversão entre construtos cognitivos não são raridade nas abordagens cognitivistas - vide a abordagem de Johnson (1987) para os esquemas imagéticos, por exemplo - a relação de Uso não é encontrada entre o frame Finalidade e os outros frames evocados pelas construções da Família Para Infinitivo, tais como Possibilidade, por exemplo.

Antes, entretanto, de passarmos às considerações decorrentes dessas questões problemáticas, analisemos mais dois exemplos de construções cuja modelagem no Constructicon do Português Brasileiro traz problemas. 


\subsubsection{O caso da Construção de Dativo com Infinitivo}

A Construção de Dativo com Infinitivo (Torrent 2009; 2015) exemplificada pela sentença (7), do corpus de audiências de conciliação do PROCON de Juiz de Fora ${ }^{12}$ - caracteriza-se por ser uma construção altamente esquemática da língua portuguesa. Apresenta o esquema sintático $\left[\mathrm{NP}_{1} \mathrm{~V} \mathrm{NP}_{2}\right.$ para $\left.\left(\mathrm{NP}_{3}\right) \mathrm{V}_{\mathrm{INF}}\right]$ quase completamente aberto, ou seja, verbos de vários tipos semânticos podem ocupar as posições de $\mathrm{V}$ e $\mathrm{V}_{\mathrm{INF}} \mathrm{O} \mathrm{NP}_{3}$ codifica um ITEM que possibilita a realização de uma SituAÇÃo_habilitadA, codificada no VP regido por para. Nesse sentido, evoca, prototipicamente, o frame Suficiência, representado na Figura 15.

(7) Ela deu mil reais pra mim fazer o serviço. (PROCON-JF)

\section{Suficiência}

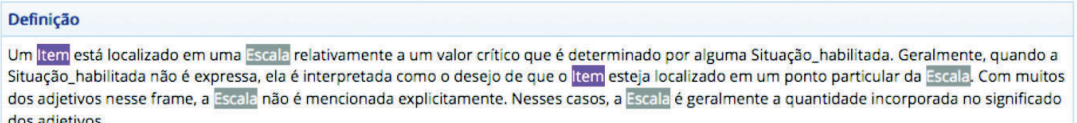

dos adjetivos nesse frame, a Escalę não é mencionada explicitamente. Nesses casos, a Escalala é geralmente a quantidade incorporada no significado dos adjetivos.

Figura 15 - Definição do frame Suficiência na FrameNet Brasil. Fonte: http:// www.framenetbr.ufjf.br/dados/vocabulario-generico.

Dentre os tipos semânticos de verbos que podem preencher o slot $\mathrm{V}$, foram encontrados verbos de atividade mental, obtenção, mudança de estado, posse e existência, exemplificados, respectivamente, nas sentenças de (8) a (12), todas extraídas do corpus Conceição de Ibitipoca $^{13}$.

(8) A senhora sabe alguma simpatia pra parar de fumar? (IBITIPOCA)

(9) Ele que arrumou a condução pra nós ir. (IBITIPOCA)

12. O corpus PROCON-JF compõe-se de audiências de conciliação no âmbito dos direitos do consumidor e foi coletado, compilado e organizado pelos professores Sônia Bittencourt Silveira, Paulo Cortes Gago e Nilza Barroso Dias, na Universidade Federal de Juiz de Fora.

13. O corpus Conceição de Ibitipoca compõe-se de entrevistas semiestruturadas gravadas com moradores da comunidade de Conceição de Ibitipoca, distrito de Lima Duarte, Minas Gerais. Foi coletado, compilado e organizado pela professora Therezinha Campos de Resende. 
(10) A senhora tem que criar coragem pra senhora cantar pras almas. (IBITIPOCA)

(11) Eles têm dinheiro para comprar a casa. (IBITIPOCA)

(12) Tem alguma coisa para ver aqui? (IBITIPOCA)

Ao ser modelada no Constructicon, a Construção de Dativo com Infinitivo foi definida por Lage (2013) como compreendendo dois ECs: o Núcleo, que pode ser mapeado ao EF IтEM do frame Suficiência, e a Sentença Infinitiva regida por Para (Para_Sinf), projetada no EF SituAÇÃo_habilitada do mesmo frame. Nesse sentido, apresenta as mesmas questões relativas à herança da Construção Adjuntiva Final Infinitiva, já exploradas na seção anterior. Por outro lado, porém, resolve a diversidade de tipos semânticos de verbos demonstrada acima, através de uma divisão de tarefas com a FrameNet Brasil: enquanto é responsabilidade da construção evocar a noção de Suficiência, cabe aos verbos a evocação de frames como Conhecimento, Obtenção, Tornar-se, Posse e Existência.

Entretanto, por adotar a solução da divisão de tarefas, a Construção de Dativo com Infinitivo suscita uma questão adicional importante: como proceder quando, da interação semântica entre verbo e construção, surgir uma nova leitura da semântica construcional? Observe-se o exemplo (13).

(13) Eu tenho outras coisas pra resolver. (IBITIPOCA)

Não seria possível atribuir a (13) uma leitura proeminentemente habilitativa, apesar de, do ponto de vista formal, a sentença parecer uma instância da Construção de Dativo com Infinitivo. Nesse caso, a leitura de modalidade deôntica é a mais evidente, o que apontaria para a evocação do frame Ser_obrigado - Figura 16.

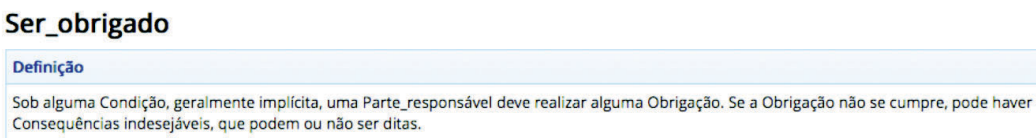

Figura 16 - Definição do frame Ser obrigado na FrameNet Brasil. Fonte: http://www.framenetbr.ufjf.br/dados/vocabulario-generico. 
Laviola (2015) argumenta que a leitura deôntica na construção de Dativo com Infinitivo ocorre quando o EC Núcleo pode ser mapeado a um EF nuclear do frame evocado pelo verbo infinitivo, geralmente na função de objeto, caso que se confirma em (13), visto que outras coisas instancia o EF nuclear Problema, no frame Resolver_problema, o qual ocorre, tipicamente como objeto direto, visto que esse frame apresenta, também como elemento nuclear, um AGENTE que ocupa, tipicamente, a posição de sujeito. Tal análise aponta para a necessidade premente de que as duas bases de dados - o Lexicon e o Constructicon da FrameNet Brasil - sejam interligadas profundamente, uma vez que apenas uma análise que considere a interação entre construções, entre frames e entre os frames evocados por itens lexicais e construções será capaz de prover uma resposta computacional satisfatória aos fenômenos linguísticos.

\subsubsection{O caso das Construções Binominais}

Por fim, para adicionar mais um viés à discussão acerca da modelagem de relações entre construções e entre frames, apresentamos nesta seção duas construções binominais do PB, quais sejam: a Construção Binominal de Quantificação Indefinida e Construção Binominal de Especificação. A primeira resulta da associação do padrão sintático $\left[\mathrm{N}_{1}\right.$ de $\mathrm{N}_{2}$ ] ao frame de Massa_quantificada. Nesta esquematização, $\mathrm{N}_{1}$ pode ser expresso como o termo quantificador da construção, enquanto $\mathrm{N}_{2}$ representa a entidade quantificada. O preenchimento do slot $\mathrm{N}_{1}$ com nomes como: caminhão, enchente, monte, pilha, avalanche, pitada, ponta, fiapo, dentre outros, gera instâncias como as sentenças (14)-(16), extraídas do corpus Cetenfolha ${ }^{14}$ :

(14) Eu acho que a responsabilidade que os votos, esse caminhão de votos está dando ao senhor nesse sentido é muito grande. (CETENFOLHA)

(15) Um verdadeiro dilúvio, uma enchente de cartas inunda a redação. (CETENFOLHA)

(16) É um mundo de mutantes superpoderosos, mas com uma pitada de realismo. (CETENFOLHA)

14. O corpus Cetenfolha é composto por textos do Jornal Folha de São Paulo e pode ser acessado através da ferramenta Sketch Engine em http://www.sketchengine.co.uk. 
Com relação à Construção Binominal de Especificação, a estrutura $\left[\mathrm{N}_{1}\right.$ de $\left.\mathrm{N}_{2}\right]$ é associada à noção de especificação. $\mathrm{N}_{1}$ corresponde ao núcleo sintático e semântico da construção, e $\mathrm{N}_{2}$, à entidade que constitui ou especifica o $\mathrm{N}_{1}$, como ilustram os exemplos (17)-(19)

(17) Os peritos policiais encontraram marcas de cal no quarto de Dayse e alguns pingos de sangue no banheiro do apartamento do sobrinho da aposentada... (CETENFOLHA)

(18) Sem-terra saqueiam caminhão de alimentos. (CETENFOLHA)

(19) Frequentemente, uma onda de energia extremamente alta, um raio gama ou cósmico das profundezas do espaço, penetra a atmosfera. (CETENFOLHA)

Comparando as duas construções, tem-se uma estrutura sintagmática semelhante $-\left[\mathrm{N}_{1}\right.$ de $\left.\mathrm{N}_{2}\right]$-, embora apresentem distinções semântico-pragmáticas e de estatuto categorial de $\mathrm{N}_{1}$. Se em monte de areia, interpreta-se de areia como um tipo específico de monte; em monte de problemas, não estamos mais falando de um monte, mas de uma grande quantidade de problemas.

Retomando-se o Princípio da Motivação Maximizada (Goldberg 1995: 67), caberia questionar como as construções acima apresentadas motivam uma a outra. Segundo Brodbeck (2010), os primeiros usos de monte associados a um complemento, como em monte de terra e monte de pedras, seriam responsáveis pela emergência da estrutura abstrata $\left[\mathrm{N}_{1}\right.$ de $\left.\mathrm{N}_{2}\right]$ associada ao frame Massa_quantificada. Novamente segundo Brodbeck (2010: 105), o que ocorre "é a reorganização semântica da expressão motivada pela metáfora (primária) MAIS É PRA CIMA, que recruta um esquema imagético piramidal, evocado pela estrutura físico-visual de monte". Diante desta reorganização, é possível conceber Quantidade em termos de Verticalidade.

Nesse sentido, depreende-se que a Construção Binominal de Quantificação Indefinida seja cognitivamente motivada pela Construção Binominal de Especificação e tenha, por isso, uma relação de herança com esta, via metáfora, corroborando o Princípio da Motivação Maximizada.

O estudo destas construções também vem reafirmar a necessidade de, ao se estabelecerem relações construção-a-construção, levar-se em 
conta, ainda, as relações frame-a-frame, uma vez que o significado da construção pode depender da interação entre o frame que esta evoca e os frames evocados pelos itens lexicais que a compõe. Ou seja, a combinação de chuva de com uma entidade como granizo, resulta numa instância da Construção Binominal de Especificação, já que chuva está evocando o frame Precipi tação. Já a combinação de chuva de com críticas gera uma expressão de Quantificação, pois chuva não poderia estar evocando Precipi tação, tendo em vista a incompatibilidade do frame evocado por críticas.

\subsubsection{Caminhos apontados pelas análises}

Dadas as análises apresentadas nas três seções anteriores, concluise que, para que o Constructicon do Português Brasileiro modele, adequadamente, as relações entre construções e entre frames observáveis na língua portuguesa, será necessário buscar contribuições de mais de uma corrente teórica da Gramática das Construções.

Primeiramente, bebendo na fonte que deu origem a todos os constructicons, relações de Herança Completa deverão ser modeladas na base de dados do Constructicon do Português Brasileiro, de modo a capturar as generalidades compartilhadas por mais de uma construção. Em segundo lugar, o Princípio da Motivação Maximizada não deve ser abandonado, em especial considerando-se sua operacionalização na proposição de laços metafóricos e de heranças múltiplas e parciais. Para tanto, novas relações entre construções e, muito provavelmente, entre frames, deverão ser criadas, ao mesmo tempo em que se deve buscar o alinhamento das FrameNet Brasil e de seu Constructicon com repositórios de metáforas, tais como a MetaNet ${ }^{15}$.

De outro lado, algumas premissas analíticas caras a alguns domínios da prática teórico-metodológica da Linguística precisarão ser abandonadas, quando se assume, em definitivo, o viés computacional. A primeira dessas premissas é a busca por um recurso completo. Nem a FrameNet Brasil, nem o Constructicon serão totalmente completos um dia. E isso não se deverá apenas à dinamicidade da língua e sua 
tendência à mudança, mas também, ao fato de que, virtualmente, toda e qualquer modelagem computacional realizada nesses dois recursos pode ser refinada em sucessivas rodadas de verticalização dos recursos.

A segunda premissa a ser abandonada, por outro lado, é a de que o Constructicon deverá conter todas as construções observáveis para o português brasileiro. Esse é o objetivo de uma Gramática das Construções, não o de um recurso sintático complementar à FrameNet Brasil. Só serão registradas no Constructicon, portanto, aquelas construções que não possam ter sua análise resumida a informações de valência de seus núcleos lexicais.

Por fim, as análises mostram que as relações entre construções nem sempre encontram-se em paralelo com relações entre frames. Construções podem ser parcialmente produtivas e, complementarmente, seu sentido pode se alterar mediante a sua interação com outros contornos semânticos. Isso não significa abandonar o Princípio da Motivação Maximizada, mas sinaliza para a necessidade de encontrar outras alternativas, que não as relações frame a frame já definidas pela Berkeley FrameNet, para operacionalizá-lo na base de dados.

\section{Considerações finais}

Neste trabalho, a partir da análise de três casos de construções já modeladas no Constructicon da FrameNet Brasil, discutimos as implicações de estender para o domínio computacional, no âmbito da FrameNet Brasil, os postulados teórico-analíticos das Gramáticas das Construções de Berkeley e Cognitivista, em especial no que tange aos diferentes conceitos de herança construcional, ao Princípio da Motivação Maximizada e à interação entre frames verbais e construcionais.

Apontamos para a necessidade de modelar computacionalmente tanto a Herança Completa como outras formas de Herança Normal na base de dados do Constructicon, ao mesmo tempo em que se fará necessário revisitar as relações entre frames propostas pela Berkeley FrameNet.

Acreditamos ter contribuído não apenas para a delimitação de políticas de tratamento de construções no domínio das framenets, dada 
a possibilidade de extrapolação dos nossos achados sobre o português brasileiro para outras línguas, mas, também, para a elucidação de questões importantes no que tange à extensão, para o viés computacional, de práticas analíticas consagradas na Linguística Cognitiva.

\section{Agradecimentos}

O projeto Frames e Construções contou com os financiamentos da Fundação de Amparo a Pesquisa do Estado de Minas Gerais, através do Programa Pesquisador Mineiro (FAPEMIG CHE-PPM-00096/13), e do Conselho Nacional de Desenvolvimento Científico e Tecnológico, através da Chamada Universal nº 14/2012 (CNPq APQ-476292/2012-3).

Recebido em setembro de 2014 Aprovado em outubro de 2015 E-mails: tiago.torrent@ufjf.edu.br lu.meireleslage@gmail.com tatyytavares@gmail.com adrielilaviola@gmail.com

\section{Referências bibliográficas}

Atrins, Sue \& Michael Rundell. 2008. The Oxford Guide to Practical Lexicography. New York: Oxford University Press.

Bäскsтröм, Linnéa; Benjamin Lyngfelt \& Emma Sköldberg. 2014. Towards interlingual constructicography: on correspondence between constructicon resources for English and Swedish. Constructions and Frames, 6 (1): 9-33.

Bergen, Benjamin \& Nancy Chang. 2013. Embodied Construction Grammar. In: Thomas Hoffmann \& Graeme Trousdale (eds.). The Oxford Handbook of Construction Grammar. New York: Oxford University Press.

Boas, Hans C. \& Ivan Sag (eds.). 2012. Sign-Based Construction Grammar. Stanford: CSLI Publications.

BRODBECK, Regina C. M. S. 2010. Um monte de problemas gera uma chuva de respostas: um estudo de caso de desencontro na quantificação nominal em português. Tese de Doutorado em Linguística. 
Universidade Federal de Juiz de Fora, Programa de Pós-Graduação em Linguística.

CROFT, William. 2001. Radical Construction Grammar. Oxford: Oxford University Press.

Fellbaum, Christiane (ed.). 1998. WordNet: an electronic lexical database. Cambridge, Mass.: MIT Press.

Ferrari, Lilian. 2011. Introdução à Linguística Cognitiva. São Paulo: Contexto.

Fillmore, Charles J. 1968. The Case for Case. In: Emmon Bach \& Richard Harms (eds.). Universals in Linguistic Theory. New York: Holt, Rinehart \& Winston.

. 1975. An alternative to checklist theories of meaning. Proceedings of the First Annual Meeting of the Berkeley Linguistics Society, 1: 123-131.

. 1982. Frame Semantics. In: The Linguistic Society of Korea (ed.). Linguistics in The Morning Calm. Seoul: Hanshin.

. 1985. Frames and the semantics of understanding. Quaderni di Semantica, 6: 222-254.

.2008a. The Merging of "Frames". In: Rema Rossini Favretti (ed.).

Frames, Corpora and Knowledge Representations. Bologna: Bononia University Press.

. 2008b. Border Conflicts: FrameNet meets Construction Grammar. In: Proceedings of EURALEX13. Barcelona: Universitat Pompeu Fabra.

. 2013. Berkeley construction grammar. In: Thomas Hoffmann \& Graeme Trousdale (eds.). The Oxford Handbook of Construction Grammar. New York: Oxford University Press.

., Christian. R. Johnson \& Miriam R. L. Petruck. 2003. Background to FrameNet. International Journal of Lexicography, 16 (3): 235250 .

Goldberg, Adele E. 1995. Constructions: A construction grammar approach to argument structure. Chicago: Chicago University Press.

. 2006. Constructions at work: The nature of generalization in language. New York: Oxford University Press.

. 2010. Verbs, Constructions and Semantic Frames. In: Malka Rappaport Hovav, Edit Doron \& Ivy Sichel (eds.). Lexical Semantics, Syntax and Event Structure. Oxford: Oxford University Press.

JoHNSON, Mark. 1987. The body in the mind: the bodily basis of meaning, imagination, and reason. Chicago: The University of Chicago Press. 
KaY, Paul. 2005. Argument Structure Constructions and The ArgumentAdjunct Distinction. In: Mirjam Fried \& Hans Boas (eds.). Grammatical Constructions: Back to the Roots. Amsterdam: Benjamins.

KAY, Paul \& Charles J. Fillmore. 1999. Grammatical constructions and linguistic generalizations: The what's $\mathrm{X}$ doing $\mathrm{Y}$ construction. Language, 75: 1-34.

Lage, Ludmila M. 2013. Frames e Construções: a implementação do Constructicon na FrameNet Brasil. Dissertação de Mestrado em Linguística. Universidade Federal de Juiz de Fora, Programa de PósGraduação em Linguística.

LANGACKer, Ronald W. 2008. Cognitive Grammar: a Basic Introduction. Oxford: Oxford University Press.

Laviola, Adrieli Bonjour. 2015. Frames e Construções em Contraste: uma análise comparativa português-inglês no tangente à implementação de constructicons. Dissertação de Mestrado em Linguística. Universidade Federal de Juiz de Fora, Programa de Pós-Graduação em Linguística.

Lyngfelt, Benjamin; Lars Borin; Markus Forsberg; Julia Prentice; Rudolf Rydstedt; Emma Sköldberg \& Sofia Tingsell. 2012. Adding a constructicon to the Swedish resource network of Språkbanken. In: Jeremy Jancsary. Ed. Empirical Methods in Natural Language Processing: Proceedings of the Conference on Natural Language Processing 2012. Vienna: ÖGAI.

OHARA, Kyoko H. 2013. Toward constructicon building for Japanese in Japanese FrameNet. Veredas, 17(1): 11-27.

RuPPENHOFER, Joseph, Michael Ellsworth, Miriam R. L. Petruck, Christopher Johnson \& Jan Scheffczyk, J. 2010. FrameNet II: extended theory and practice. Berkeley: International Computer Science Institute.

SAlomão, Maria Margarida M. 2009. FrameNet Brasil: um trabalho em progresso. Calidoscópio, 7 (3): 171-182.

Tavares, Tatiane Silva. 2014. Construção Binominal de Quantificação Indefinida no Português - uma abordagem construcionista. Dissertação de Mestrado em Linguística. Universidade Federal de Juiz de Fora, Programa de Pós-Graduação em Linguística.

Torrent, Tiago Timponi. 2009. A Rede de Construções em Para (SN) Infinitivo: uma abordagem centrada no uso para as relações de herança e mudança construcionais. Tese de Doutorado em Linguística. Universidade Federal do Rio de Janeiro, Programa de Pós-Graduação em Linguística.

2015. On the Relation between Inheritance and Change: 
Reconfiguration hypotheses. In: Jóhanna Barðdal, Elena Smirnova, Lotte Sommerer, \& Spike Gildea (eds.). Diachronic Construction Grammar. Amsterdam / New York: John Benjamins.

. \& Michael Ellsworth. 2013. Behind the labels: criteria for defining analytical categories in FrameNet Brasil. Veredas, 17 (1): 44-65.

, Ludmila M. Lage; Thaís F. Sampaio; Tatiane S. Tavares \& Ely E. S. Matos. 2014. Revisting border conflicts between FrameNet and Construction Grammar: annotation policies for the Brazilian Portuguese Constructicon. Constructions and Frames, 6 (1): 34-51. 
Tiago T. Torrent, Ludmila M. Lage, Tatiane S. Tavares, Adrieli B. Laviola 